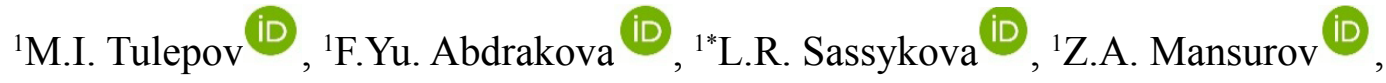

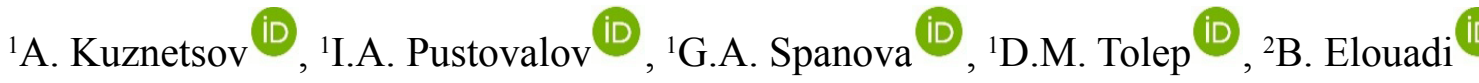 \\ ${ }^{1}$ Institute of Combustion Problems, 172, Bogenbai, Batyr St., 050000, Almaty, Kazakhstan \\ ${ }^{2}$ Université De La Rochelle, Technoforum, 23 ave. Albert Einstein, \\ BP 33060 - 17031, La Rochelle, France \\ "e-mail: larissa.rav@mail.ru

\section{Modeling of the explosion of pyroxylin or combustion of the pyrotechnic composition}

\begin{abstract}
Considering the blow force as the given parameter during the combustion of pyrotechnic compositions, it is possible to calculate the mass of a necessary charge of pyrotechnic formulation. By this cause, a special interest is the model of an explosion or burning of the pyrotechnic composition, in which is possible at high degree of accuracy to calculate the mass of the pyrotechnic charge. This will lower the percentage of accidents when dealing with pyrotechnics. The aim of the work is formulation of the physical and mathematical model of explosion or combustion of pyrotechnic composition on the basis of laws of conservation of momentum and energy. The calculation formulas were checked on a concrete example - pyroxylin and compared with data from reference books and the Internet. The analysis of a calculated formula for a pyroxylin showed that in the course of explosion the main contribution to destruction of the chosen objects is made by a potential energy of gases (about $88 \%$ ), and only $12 \%$ by a kinetic energy of incandescent gases, but when calculating force of explosion it needs to be considered.

Key words: explosion, combustion, pyroxylin, energy, momentum, the physical and mathematical model of explosion or combustion of pyrotechnic composition.
\end{abstract}

\section{Introduction}

Combustion explosive gas (or fluid) mixtures or individual explosives is a homogeneous combustion. Pyrotechnic compositions are the mechanical mixtures of the solid, finely crushed components - on degree of homogeneity are in the middle between the condensed fuel and individual substances (or homogeneous mixtures). Combustion of pyrotechnic compositions is carried out by a heat transfer from a reaction zone, to layers in which there is a preparation for combustion process. Inflaming of pyrocompositions also is based on the same principle. For emergence of combustion it is necessary to create local temperature increase in composition; it is reached by usually immediate impact on composition of hot gunpowder gases or use of special flammable formulations. When the pyrocomposition is put in action by a fire impulse and its combustion takes place in open space, its burning rate is small (usually a few $\mathrm{mm} / \mathrm{s}$ ). If the combustion occurs in an enclosed space, or if used in as an initiator a detonator cap, it may be an explosion (which speed is measured in hundreds, and sometimes thousands of $\mathrm{m} / \mathrm{s}$ ) [1-8].
There are many ways of calculation and choice of necessary explosive, for carrying out blasting, production of pyrotechnic devices, etc. These are chemical ways where calculations are carried out through an explosive decomposition reaction; physical ways where many researchers solve this problem as a problem only of thermal explosion. Explosion modeling assumes the solution of this problem, through the laws of conservation of energy and momentum, that allows to see visually the role introduced by each component in the reaction equations of conservation of energy and momentum [9-13].

In the solution of the equation the blow force necessary for destruction of this material is especially highlighted, using it as the given parameter, it is possible to specify enough the mass of a necessary charge of pyrotechnic formulation [14-18].

Therefore, a special interest is the model of an explosion or burning of the pyrotechnic composition, in which is possible at high degree of accuracy to calculate the mass of the pyrotechnic charge. This will lower the percentage of accidents when dealing with pyrotechnics, when dealing with 
pyrotechnics that may arise on fault of the manufacturer, as well as to reduce the percentage of systematic deviation from the intended accuracy of blasting and other work associated with the pyrotechnic compositions.

The aim of the work is formulation of the physical and mathematical model of explosion or combustion of pyrotechnic composition on the basis of laws of conservation of momentum and energy.

\section{Experimental}

Physical and mathematical modeling of chemical and physical reactions is a way to describe a physical and chemical phenomenons, using the equations of mathematical physics, usually under the terms of an approximation to the real phenomenon. Physical and mathematical model is necessary for the study of chemical and physical phenomena in the laboratory, i.e. on the equipment, which is created with the specified parameters, and which reproduces the studied physical phenomenon [19-21]. If there are difficulties with reproduction and the description of the physical phenomenon, because of complexity of a physical task, then usually use similarity of the phenomena in which the solution of a task considerably becomes simpler, and the resulting mathematical decision for the description of the studied physical phenomenon is used.

For burning modeling, or explosion of pyrotechnic formulation, it is necessary to use the conservation equations:

$$
\frac{\mathrm{d}}{\mathrm{dt}} \sum_{\mathrm{i}=1}^{\mathrm{n}}\left(\mathrm{m}_{\mathrm{i}} * \overrightarrow{\mathrm{v}}_{\mathrm{i}}\right)=0
$$

where $\mathrm{n}=1,2,3,4,5, \ldots$

The equation (1) is the law of conservation of momentum, $\mathrm{m}_{\mathrm{i}}, \overrightarrow{\mathrm{v}}_{\mathrm{i}}$ - the weight and speed of the $\mathrm{i}_{\text {-th }}$ component of system, before and after the explosion.

$$
\frac{\mathrm{d}}{\mathrm{d} \mathrm{t}} \sum_{\mathrm{i}=1}^{\mathrm{n}} \mathrm{E}_{\mathrm{i}}=0
$$

where $E^{i}-$ the total energy of the system, and the equation (2) is the law of conservation of energy.

Let's transform, the equation of conservation of momentum, for this purpose use differentiation in private derivatives, on variable coordinates $\overrightarrow{\mathrm{r}}, \mathrm{t}-$ radius of the vector, and of time

Int. j. biol. chem. (Online)

$$
\begin{gathered}
\frac{\mathrm{d}}{\mathrm{dt}} \sum_{\mathrm{i}=1}^{\mathrm{n}}\left(\mathrm{m}_{\mathrm{i}} * \overrightarrow{\mathrm{v}}_{\mathrm{i}}\right)=\sum_{\mathrm{i}=1}^{\mathrm{n}} \mathrm{m}_{\mathrm{i}} *\left(\frac{\partial}{\partial \mathrm{t}} \overrightarrow{\mathrm{v}}_{\mathrm{i}}+\frac{\partial \overrightarrow{\mathrm{r}}^{2}}{\partial \mathrm{t}} * \frac{\partial}{\partial \overrightarrow{\mathrm{r}}} \overrightarrow{\mathrm{v}}_{\mathrm{i}}\right)+ \\
+\sum_{\mathrm{i}=1}^{\mathrm{n}} \overrightarrow{\mathrm{v}}_{\mathrm{i}} *\left(\frac{\partial}{\partial \mathrm{t}} \mathrm{m}_{\mathrm{i}}+\frac{\partial \vec{r}}{\partial \mathrm{t}} * \frac{\partial}{\partial \overrightarrow{\mathrm{r}}} \mathrm{m}_{\mathrm{i}}\right)=0
\end{gathered}
$$

The two parts of the equation (3) can be equalized and rewritten as:

$$
\begin{aligned}
& \sum_{i=1}^{n} m_{i} *\left(\frac{\partial}{\partial t} \vec{v}_{i}+\frac{\partial \vec{r}}{\partial t} * \frac{\partial}{\partial \vec{r}} \vec{v}_{i}\right)= \\
= & -\sum_{i=1}^{n} \vec{v}_{i} *\left(\frac{\partial}{\partial t} m_{i}+\frac{\partial \vec{r}}{\partial t} * \frac{\partial}{\partial \vec{r}} m_{i}\right)
\end{aligned}
$$

If to add variables as multipliers, under a sign of private derivatives, then we will obtain the equation (4) in a semi-logarithmic form:

$$
\begin{aligned}
& \sum_{i=1}^{n}\left(\frac{\partial}{\partial t} \operatorname{Ln}\left(\vec{v}_{i}\right)+\frac{\partial \vec{r}}{\partial t} * \frac{\partial}{\partial \vec{r}} \operatorname{Ln}\left(\vec{v}_{i}\right)\right)= \\
= & -\sum_{i=1}^{n}\left(\frac{\partial}{\partial t} \operatorname{Ln}\left(m_{i}\right)+\frac{\partial \vec{r}}{\partial t} * \frac{\partial}{\partial \vec{r}} \operatorname{Ln}\left(m_{i}\right)\right)
\end{aligned}
$$

Let's group in the equation (5) parts identical on derivatives and we will highlight a derivative in the right part of equation (5) $\frac{\partial \vec{r}}{\partial t}$ :

$$
\begin{gathered}
\sum_{i=1}^{n}\left(\frac{\partial}{\partial t} \operatorname{Ln}\left(\vec{v}_{i}\right)+\frac{\partial}{\partial t} \operatorname{Ln}\left(m_{i}\right)\right)= \\
=-\frac{\partial \vec{r}}{\partial t} * \sum_{i=1}^{n}\left(\frac{\partial}{\partial \vec{r}} \operatorname{Ln}\left(\vec{v}_{i}\right)+\frac{\partial}{\partial \vec{r}} \operatorname{Ln}\left(m_{i}\right)\right)
\end{gathered}
$$

So multiply private derivatives on equal in brackets:

$$
\begin{aligned}
& \sum_{i=1}^{n}\left(\frac{\partial}{\partial t} \operatorname{Ln}\left(\vec{v}_{i}\right)+\frac{\partial}{\partial t} \operatorname{Ln}\left(m_{i}\right)\right) \partial t= \\
= & -\sum_{i=1}^{n}\left(\frac{\partial}{\partial \vec{r}} \operatorname{Ln}\left(\vec{v}_{i}\right)+\frac{\partial}{\partial \vec{r}} \operatorname{Ln}\left(m_{i}\right)\right) \partial \vec{r}
\end{aligned}
$$

As private derivatives with different variables are partitioned on the different sides of the equation (7) and in each part differentiation on one variable is made, it is possible on properties of private derivatives, to pass from private derivatives to differentials:

$$
\begin{aligned}
& \sum_{i=1}^{n}\left(\frac{d}{d t} \operatorname{Ln}\left(\vec{v}_{i}\right)+\frac{d}{d t} \operatorname{Ln}\left(m_{i}\right)\right) d t= \\
= & -\sum_{i=1}^{n}\left(\frac{d}{d \vec{r}} \operatorname{Ln}\left(\vec{v}_{i}\right)+\frac{d}{d \vec{r}} \operatorname{Ln}\left(m_{i}\right)\right) d \vec{r}
\end{aligned}
$$


Let's make reduction in both members of equation and will integrate the equation (8):

$$
\begin{aligned}
& \sum_{i=1}^{n} \int\left(d \operatorname{Ln}\left(\vec{v}_{i}\right)+d \operatorname{Ln}\left(m_{i}\right)\right)= \\
= & -\sum_{i=1}^{n} \int\left(d \operatorname{Ln}\left(\vec{v}_{i}\right)+d \operatorname{Ln}\left(m_{i}\right)\right)
\end{aligned}
$$

For convenience of transformation, the constants obtained at integration have presented in the logarithmic form:

$$
\begin{aligned}
& \sum_{i=1}^{n} \operatorname{Ln}\left(\vec{v}_{i} * m_{i}\right)+\operatorname{LnC}_{1}= \\
& =-\sum_{i=1}^{n} \operatorname{Ln}\left(\vec{v}_{i} * m_{i}\right)+\operatorname{LnC} C_{2}
\end{aligned}
$$

Let's raise the right and left member of equation in degree on the basis of a constant of Napyer:

$$
\begin{aligned}
& \exp \left[\sum_{i=1}^{n} \operatorname{Ln}\left(\mathrm{C}_{1} * \overrightarrow{\mathrm{v}}_{\mathrm{i}} * \mathrm{~m}_{\mathrm{i}}\right)\right]= \\
& =\exp \left[\sum_{\mathrm{i}=1}^{\mathrm{n}} \operatorname{Ln}\left(\frac{\mathrm{C}_{2}}{\overrightarrow{\mathrm{v}}_{\mathrm{i}}^{*} \mathrm{~m}_{\mathrm{i}}}\right)\right]
\end{aligned}
$$

As we have no determining factors for the constants obtained in case of integration, will continue transformations of the equation, and we will determine constants according to the energy conservation law in an integrated type:

$$
\mathrm{C}_{1} * \sum_{\mathrm{i}=1}^{\mathrm{n}} \overrightarrow{\mathrm{v}}_{\mathrm{i}} * \mathrm{~m}_{\mathrm{i}}=\frac{\mathrm{C}_{2}}{\sum_{\mathrm{i}=1}^{\mathrm{n}} \overrightarrow{\mathrm{v}}_{\mathrm{i}} * \mathrm{~m}_{\mathrm{i}}}
$$

Let's take out constants to the right side of the equation:

$$
\sum_{i=1}^{n}\left(\vec{v}_{i} * m_{i}\right)^{2}=\frac{\mathrm{C}_{2}}{\mathrm{C}_{1}}
$$

We will reduce the degree of the left side of the equation (13):

$$
\sum_{i=1}^{n}\left(\vec{v}_{i} * m_{i}\right)=\sqrt{\frac{\mathrm{C}_{2}}{\mathrm{C}_{1}}}
$$

where $\mathrm{C}_{1} \neq 0$, on the problem statement $\mathrm{C}_{2}=0$

Int. j. biol. chem. (Online)
Law of conservation of momentum in an integrated form is obtained:

$$
\sum_{i=1}^{n}\left(\vec{v}_{i} * m_{i}\right)=0
$$

Since, in the course of the explosion involved three components of the system (an explosive, gases produced at the chain reaction, and solid residues), that for our case $n=3$

$$
\overrightarrow{\mathrm{v}}_{1} * \mathrm{~m}_{1}=-\overrightarrow{\mathrm{v}}_{2} * \mathrm{~m}_{2}-\overrightarrow{\mathrm{v}}_{3} * \mathrm{~m}_{3}
$$

where $\left|\vec{v}_{1}\right|=\left|\vec{v}_{2}\right|=\left|\vec{v}_{3}\right|$

$$
\mathrm{m}_{1}=\mathrm{m}_{2}+\mathrm{m}_{3}
$$

where $\mathrm{m}_{1}$ is weight of explosive charge, $\mathrm{m}_{2}$ is resulting gases mass, $m_{3}$ is the cooling solid product of the explosion. In order to find the sought variable - volume of gases produced during the flow of the chain reaction it is necessary to present the mass through density and the occupied substance volume

$$
\rho_{1} * \mathrm{~V}_{1}=\rho_{2} * \mathrm{~V}_{2}+\rho_{3} * \mathrm{~V}_{3}
$$

Let's transfer a required variable to the left side of the equation (18):

$$
\rho_{2} * \mathrm{~V}_{2}=\rho_{1} * \mathrm{~V}_{1}-\rho_{3} * \mathrm{~V}_{3}
$$

After simple mathematical transformations, we obtain an equation that determines the desired value:

$$
\mathrm{V}_{2}=\frac{\rho_{1} * \mathrm{~V}_{1}-\rho_{3} * \mathrm{~V}_{3}}{\rho_{2}}=\frac{\mathrm{m}_{1}-\mathrm{m}_{3}}{\rho_{2}}
$$

where $\rho_{1}$ is stoichiometric density of the explosive charge, $\rho_{2}$ is density the produced gases at an actual temperature, $\rho_{3}$ is the density of the combustion residue.

$\mathrm{V}_{1}, \mathrm{~V}_{2}, \mathrm{~V}_{3}$ are the corresponding volumes.

Since $V_{2}$ is the volume of gases, and is searched at N.C. (normal conditions), then at solution of the problem it is necessary volume of gases result to the real conditions, i.e. to a temperature equal to about $2500 \mathrm{~K}$, for pyroxylin, and to the selected volume $\mathrm{V}$ (pressing of a pyroxylin by volume $\mathrm{V}$ is possible), $\mathrm{p}_{1}, \mathrm{p}_{2}$ - the atmospheric pressure and $v_{1}=v_{2}$. 
For the analysis of the obtained specified value the volume of gases needs to be given to N.C., then it is necessary to use the state equations for gases:

$$
\begin{array}{r}
\left\{\begin{array}{c}
\mathrm{P}_{2} * \mathrm{~V}_{2}^{\prime}=v_{2} * \mathrm{R} * \mathrm{~T}_{2}^{\prime} \\
\mathrm{P}_{2} * \mathrm{~V}_{2}=v_{2} * \mathrm{R} * \mathrm{~T}_{2}
\end{array}\right. \\
\mathrm{V}_{2}^{\prime}=\frac{q * \mathrm{~V}_{1}-\rho_{3} * \mathrm{~V}_{3}}{\rho_{2}} * \frac{\mathrm{T}_{2}^{\prime}}{\mathrm{T}_{2}}=\frac{\mathrm{m}_{1}-\mathrm{m}_{3}}{\rho_{2}} * \frac{\mathrm{T}_{2}^{\prime}}{\mathrm{T}_{2}}
\end{array}
$$

where $\mathrm{T}_{2}{ }_{2}$ is a temperature of normal conditions $(293,16 \mathrm{~K}), T_{2}$ is a temperature of incandescent gas (2,500 K for pyroxylin).

For the projectile having the volume of $\mathrm{V}$ we can lead the equation (20) to a form, it will help to estimate the value of pressure of gases upon projectile walls, as characterizes explosion:

$$
\begin{array}{r}
\left\{\begin{array}{l}
\mathrm{P} * \mathrm{~V}=v_{2} * \mathrm{R} * \mathrm{~T}_{2} \\
\mathrm{P}_{2} * \mathrm{~V}_{2}=v_{2} * \mathrm{R} * \mathrm{~T}_{2}
\end{array}\right. \\
\mathrm{P} * \mathrm{~V}=\mathrm{P}_{2} * \frac{\rho_{1} * \mathrm{~V}_{1}-\rho_{3} * \mathrm{~V}_{3}}{\rho_{2}}, \\
\mathrm{P} * \mathrm{~V}=\mathrm{P}_{2} * \frac{\mathrm{m}_{1}-\mathrm{m}_{3}}{\rho_{2}}=\mathrm{P}_{2} * \frac{\mathrm{m}_{2}}{\rho_{2}}
\end{array}
$$

in this equation is considered the pressure $\mathrm{P}$ and temperature $\mathrm{T}$ in real conditions, the formation of gas in the projectile, in a chain reaction.

Transform the energy balance equation:

$$
\sum_{i=1}^{n} E_{i}=\sum_{i=1}^{n}\left(E_{k i}+\ddot{I}_{i}\right)
$$

the total energy is the sum of kinetic and potential energy.

To obtain the necessary equations substitute the equation (25) into equation (2):

$$
\begin{gathered}
\frac{\mathrm{d}}{\mathrm{dt}} \sum_{\mathrm{i}=1}^{\mathrm{n}} \mathrm{E}_{\mathrm{i}}=\sum_{\mathrm{i}=1}^{\mathrm{n}}\left(\frac{\partial}{\partial \mathrm{t}} \mathrm{E}_{\mathrm{ki}}+\frac{\partial \overrightarrow{\mathrm{r}}}{\partial \mathrm{t}} * \frac{\partial}{\partial \overrightarrow{\mathrm{r}}} \mathrm{E}_{\mathrm{ki}}\right)+ \\
+\sum_{\mathrm{i}=1}^{\mathrm{n}}\left(\frac{\partial}{\partial \mathrm{t}} \Pi_{\mathrm{i}}+\frac{\partial \overrightarrow{\mathrm{r}}}{\partial \mathrm{t}} * \frac{\partial}{\partial \overrightarrow{\mathrm{r}}} \Pi_{i}\right)=0
\end{gathered}
$$

Since potential energy change with time and kinetic energy on radius to a vector is equal to zero, the equation (26) is given to a form:

Int. j. biol. chem. (Online)

$$
\frac{\mathrm{d}}{\mathrm{dt}} \sum_{\mathrm{i}=1}^{\mathrm{n}} \mathrm{E}_{\mathrm{i}}=\sum_{\mathrm{i}=1}^{\mathrm{n}}\left(\frac{\partial}{\partial \mathrm{t}} \mathrm{E}_{\mathrm{ki}}+\frac{\partial \overrightarrow{\mathrm{r}}}{\partial \mathrm{t}} * \frac{\partial}{\partial \overrightarrow{\mathrm{r}}} \ddot{I}_{i}\right)=0
$$

Multiply the left and right side of the equation (27) on the partial derivative, by time

$$
\sum_{i=1}^{n}\left(\frac{\partial}{\partial t} \mathrm{E}_{k i}+\frac{\partial \overrightarrow{\mathrm{r}}}{\partial \mathrm{t}} * \frac{\partial}{\partial \overrightarrow{\mathrm{r}}} \ddot{\mathrm{I}} \text { i }\right) \partial \mathrm{t}=0
$$

Reduce by a multiplier present an expression to the total differentials

$$
\sum_{i=1}^{n}\left(\mathrm{dE}_{\mathrm{ki}}+\mathrm{dI}{ }_{i}\right)=0
$$

Integrate the equation (29)

$$
\sum_{i=1}^{n} \int_{0}^{E_{k i}} d_{k i}+\sum_{i=1}^{n} \int_{0}^{\ddot{I}} d \ddot{I}_{i}=0
$$

We obtain the equation of the energy balance in the integral form:

$$
\sum_{i=1}^{n} E_{k i}+\sum_{i=1}^{n} \ddot{I}_{i}=0
$$

As in the model system are involved three bodies - an explosive gas, solid residue, then $n=3$.

$$
\sum_{i=1}^{3} \mathrm{E}_{\mathrm{ki}}+\sum_{\mathrm{i}=1}^{3} \ddot{\mathrm{I}}_{\mathrm{i}}=0
$$

Let's consider work which is made by potential force at expansion of the formed gases

$$
\delta A=\overrightarrow{\mathrm{F}} * \mathrm{~d} \overrightarrow{\mathrm{r}}=\mathrm{P} * \mathrm{dV}
$$

where $\mathrm{P}$ is defined from a formula (24).

On the other hand

$$
\overrightarrow{\mathrm{F}} * \mathrm{~d} \overrightarrow{\mathrm{r}}=-\frac{\mathrm{d} \varphi}{\mathrm{d} \overrightarrow{\mathrm{r}}} * \mathrm{~d} \overrightarrow{\mathrm{r}}=-\mathrm{d} \varphi
$$

Then potential can be presented in the form

$$
\varphi=-\mathrm{P} * \int_{\mathrm{V}}^{0} \mathrm{dV}=\mathrm{P} * \mathrm{~V}, \mathrm{~A}=\overrightarrow{\mathrm{F}} * \overrightarrow{\mathrm{r}}
$$

where $\mathrm{S}$ is the surface area of the projectile. 
Then the equation of balance taking into account the potential energy, the equation (34)

$$
\mathrm{q} * \mathrm{~m}_{1}=\frac{\mathrm{m}_{2}}{\mu_{2}} * \frac{3}{2} * \mathrm{R} * \mathrm{~T}+\mathrm{P} * \mathrm{~V}+\mathrm{c} * \mathrm{~m}_{3} *\left(\mathrm{~T}_{2}-\mathrm{T}_{2}^{\prime}\right)
$$

where $\mathrm{q}$ is the specific heat of combustion.

Substitute the formula (24) in the (35) and obtain:

$$
\begin{aligned}
& \mathrm{q} * \mathrm{~m}_{1}-\mathrm{c} * \mathrm{~m}_{3} *\left(\mathrm{~T}_{2}-\mathrm{T}^{\prime}{ }_{2}\right)= \\
& =\frac{\mathrm{m}_{2}}{\mu_{2}} * \frac{3}{2} * \mathrm{R} * \mathrm{~T}_{2}+\mathrm{P}_{2} * \frac{\mathrm{m}_{2}}{\rho_{2}}
\end{aligned}
$$

$m_{3}$ via $m_{1}$ it is possible to express via a ratio:

$$
\mathrm{m}_{3}=\mathrm{k} * \mathrm{~m}_{1}
$$
form:

Then the equation (36) can be transformed to a

$$
\mathrm{m}_{1}=\mathrm{m}_{2} * \frac{\left[\frac{3 * \mathrm{R} * \mathrm{~T}_{2}}{2 * \mu_{2}}+\frac{\mathrm{P}_{2}}{\rho_{2}}\right]}{\left[\mathrm{q}-\mathrm{c} * \mathrm{k} *\left(\mathrm{~T}_{2}-\mathrm{T}_{2}^{\prime}\right)\right]}
$$

So, a formula of the choice of mass of a charge, with respect to these conditions, have obtained, here the most important parameter is the mass of gases which can be determined by the power of the explosion needed, for example, blasting operations, according to the formula (34), into which is necessary to substitute the formula (24)

$$
\mathrm{A}=\overrightarrow{\mathrm{F}} * \overrightarrow{\mathrm{r}}=\mathrm{P}_{2} * \frac{\mathrm{m}_{2}}{\rho_{2}}
$$

here $\overrightarrow{\mathrm{F}}$ is an impact force in Newtons, necessary for material destruction, $\overrightarrow{\mathrm{r}}$ is the radius vector which is carried out from the beginning of coordinates to a point of application of force.

Now we will transform the equation (39)

$$
\mathrm{m}_{2}=\mathrm{A} * \frac{\rho_{2}}{\mathrm{P}_{2}}
$$

Then we can transform a formula (38)

$$
\mathrm{m}_{1}=\mathrm{A} * \frac{\rho_{2}}{\mathrm{P}_{2}} * \frac{\left[\frac{3}{2 * \mu_{2}} * \mathrm{R} * \mathrm{~T}_{2}+\frac{\mathrm{P}_{2}}{\rho_{2}}\right]}{\left[\mathrm{q}-\mathrm{c} * \mathrm{k} *\left(\mathrm{~T}_{2}-\mathrm{T}^{\prime}{ }_{2}\right)\right]}
$$

\section{Results and Discussions}

Let's carry out the analysis of the obtained decision on the basis of pyroxylin. It is well known that pyroxylin is a product of the complete esterification of cellulose with nitric acid (trinitrocellulose). Pyroxylin is an explosive used in the manufacture of smokeless powder [22]. For this mathematical analysis it is necessary to know which gases and the solid residue, their quantity are formed as explosion derivatives, or burning, usually for different pyrotechnic formulations they are different and also have different volume in relation to unit of mass [14-16].

For smokeless gunpowder the composition of gases has the following contents in relation to the total amount of gases: $\mathrm{H}_{2} \mathrm{O}-16 \%, \mathrm{H}_{2}-20 \%, \mathrm{~N}_{2}-$ $11 \%, \mathrm{CO}-37 \%, \mathrm{C}_{2} \mathrm{H}_{4}-1 \%, \mathrm{CO}_{2}-15 \%$, with a density of $1.214 \mathrm{~kg} / \mathrm{m}^{3}$ (under normal conditions) and with a molar weight of $23.6 \mathrm{~kg} / \mathrm{mol}$. The solid residue usually for pyroxylin is equal to from 0.1 to $0.5 \%$ by weight of the charge [17-19]. The specific heat of combustion of pyroxylin $\mathrm{q}=2,5 \mathrm{MJ} / \mathrm{kg}$, the combustion temperature is $\mathrm{T}=2500 \mathrm{~K}$, temperature of NC (normal conditions, the environment) $\mathrm{T}^{\prime}=293,16$, and $\mathrm{P}_{2}=101 \mathrm{kPa}, \mathrm{R}=8.314 \mathrm{~J} /(\mathrm{kmol} \cdot \mathrm{K})$ - the universal gas constant [5, 9, 20-27].

To check the estimated formula (20) it is necessary to set the charge weight $\mathrm{m}_{1}=0,001$ êã knowing other parameters it is possible to calculate $\mathrm{V}$ is the volume of gases, when burning gunpowder, for this purpose in a formula (20), density of gases is led to real conditions

$$
\begin{gathered}
\mathrm{V}_{2}=\frac{\mathrm{m}_{1}-\mathrm{m}_{3}}{\rho_{2}} * \frac{\mathrm{T}}{\mathrm{T}^{\prime}}=\frac{0,999 * \mathrm{~m}_{1}}{\rho_{2}} * \frac{\mathrm{T}}{\mathrm{T}^{\prime}}= \\
=\frac{0,999 * 0,001}{1,214} * \frac{293,16}{2500}=9,65 * 10^{-5} \mathrm{M}^{3}
\end{gathered}
$$

To compare the obtained results with literary data, it is necessary the volume of gases under real conditions of $\mathrm{T}=2500 \mathrm{~K}$, to lead to water freezing temperature $\mathrm{T}=273.16 \mathrm{~K}$ 


$$
\begin{gathered}
\mathrm{V}_{2}^{\prime}=\mathrm{V}_{2} * \frac{\mathrm{T}}{\mathrm{T}_{0}}=1,1 * 10^{-4} * \frac{2500}{273,16}= \\
=0,883 * 10^{-3} \mathrm{M}^{3}
\end{gathered}
$$

that within $2.0 \%$ of an error of measurement is in the range of literary data [19].

The objective of this work is the calculation of the charge of pyrotechnic substances (pyroxylin), depending on the required force of the explosion, as well as the volume of the projectile. The formula (41) obtained in the research allows to calculate the required weight of the charge $\mathrm{m}_{\mathrm{i}}$, depending on the work A of the thermodynamic system, or force from the explosion $\overrightarrow{\mathrm{F}}$, at the chosen value of radius vector $\vec{r}$, i.e. of the selected parameters of impact by explosion (the main direction of the explosion force, the distance).

The analysis of a formula (41) can be carried out on a concrete example, by means of a function graph, fig. 1 , and $\mathrm{m}_{1}=\mathrm{f}(\overrightarrow{\mathrm{F}}, \overrightarrow{\mathrm{r}})$, fig.2.

In fig. 1 dependence of mass of a charge of a pyroxylin on the work made by gases at expansion is obtained. The function graph is presented by direct proportionality, it allows to count rather precisely the mass of pyrotechnic formulation, excepting various kinds of accidents.

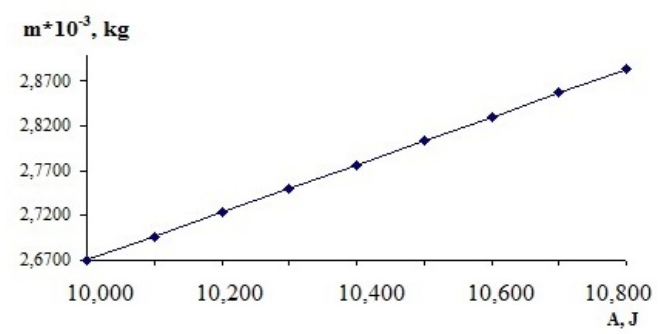

Figure 1 - The dependence of the charge weight from the explosion force

In the fig. 2 the same dependence, but in threedimensional form is set, here serve as parameters force making work (explosion) and radius the vector having the direction to a point of application where a surface area is the work made by force of expansion of incandescent gases. Analysis of the formula (41) showed that during the explosion a major contribution to the destruction of objects makes the potential energy of gas, about $88 \%$, and only $12 \%$ makes the kinetic energy of incandescent gases. Of course, when calculating force of explosion it needs to be considered. The energy

Int. j. biol. chem. (Online) introduced by solid residue, on cooling, is very small - about $0.05 \%$ and so it, in the calculations, may be neglected [28-32]. Unfortunately, in some references calculated formulas are obtained either for kinetic, or for a potential component of a calculated formula of explosion, that is the contribution made by both components of a calculated formula is underestimated.

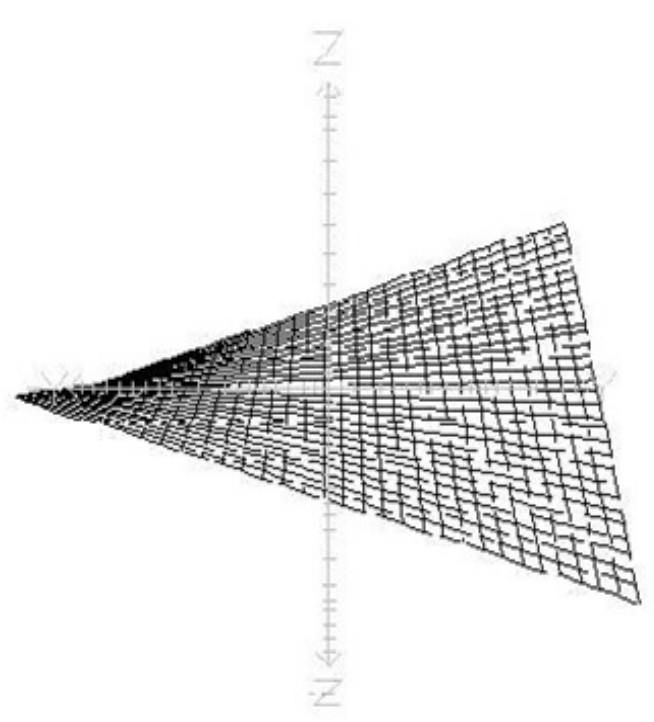

Figure 2-The dependence of weight of a charge from a force and radius vector

\section{Conclusions}

The physical and mathematical model of explosion or combustion of pyrotechnic composition on the basis of laws of conservation of momentum and energy is obtained. Calculation formulas were checked on a concrete example pyroxylin and compared with data from reference books and the Internet. This model, or calculated formula of a method, is intended for use, at manufacture of pyrotechnic substances, and also when carrying out blasting on mineral deposits, etc. It was showed that in the course of explosion the main contribution to destruction of the chosen objects is made by a potential energy of gases (about $88 \%$ ), and only $12 \%$ by a kinetic energy of incandescent gases, but when calculating force of explosion it needs to be considered.

\section{References}

1. Beck M.W., Brown M.E., Combustion and Flame, 1986, 66(1), 67. 
2. Shu-gang C.,Yan-bao L., Yan-ping W., $J$. Min. Technol., 2008, 18, 0172-0176.

3. Coleman P.J., Journal of Safety Research, 2007, 38, 523-533.

4. Riba S. J., Lesaoana M., Sigauke C., Makwela M. R., Journal of Geology and Mining Research, 2011, 3(1), 188-192.

5. Tulepov M.I., Baiseitov D.A., Gabdrashova Sh.E., Sassykova L.R., Kazakov Y.V., Tursynbek S., Toshtay K., Pustovalov I.O., Abdrakova F.Y., Mansurov Z.A., Dalton A.B., Rasayan J. Chem., 2017, 10(4), 1145-1150.

6. Sullivan M.J., Stewart W.F., Belanger D.L., SPE Annual Technical Conference and Exhibition Dallas, Texas, 2000. http://dx.doi.org/10.2118/62979-MS.

7. Sullivan M.J., Belanger D.L., Stewart W.F., SPE Reservoir Evaluation \& Engineering, 2002, 5, 60-67. http://dx.doi.org/10.2118/76643-PA.

8. Banahene A.O., Pepe D.C., Lueck W.R., SPE Rocky Mountain Petroleum Technology Conference, Keystone, Colorado, 2001. http://dx.doi.org/10.2118/71075-MS.

9. Tulepov M. I., Mansurov Z.A., Kazakov Y.V., Abdrakova F.Y., Sultanova Z.L., Rakhova N. M., Madiyev S.S., Golovchenko O.Y., Sassykova L.R., Tolep D.M., Chikhradze N., Chikhradze M.N., Oriental Journal of Chemistry, 2018, 34(6), 30373043. http://dx.doi.org/10.13005/ojc/350103.

10. Bondarev E.A., SPE Russian Oil and Gas Technical Conference and Exhibition, Moscow, Russia, 2006. http://dx.doi.org/10.2118/104331-MS.

11. Tulepov M., Baiseitov D., Sassykova L., Kazakov Y., Gabdrashova Sh., Mansurov Z., Dalton A., Journal of Chemical Technology \& Metallurgy, 2018, 53(2), 281-288.

12. Gürocak H.B., International Journal of Mechanical Engineering Education, 1998, 26(3), 210-222.

13. Abdelhamid T. S., Everett J. G., Journal of Construction Engineering \& Management, 2000, 126(1), 52.

14. Lu Kai-Tai, Yang Ching-Chyuan, Propellants, Explosives, Pyrotechnics, 2008, 33(5), 403-410.

15. Dem'yanenko D. B., Dudyrev A. S., Efanov V. V., Strakhov G., Tsinbal M. N., Solar System Research, 2013, 47(7), 508-512.

16. Podkopaev S., Sakhno S., $J$ of Donetsk Mining Institute, 2018, 1, 61-68. https://doi.org/10.31474/1999-981x-2018-1-61-68.

17. Sari M., Duzgun H.S.B., Karpuz C., Selcuk A.S., Saf. Sci., 2004, 42, 675-690.
18. Haslam R. A., Hide S. A., Gibb A. G. F., Gyi D. E., Pavitt T., Atkinson S., Duff A. R., Applied Ergonomics, 2005, 36(4), 401-415.

19. Soares A.C., Ferreira F.H., Vargas E.A., SPE Reservoir Evaluation \& Engineering, 2002, 5(6), SPE80614-PA, https://doi.org/10.2118/80614-PA.

20. Baiseitov D.A., Tulepov M. I., Tursynbek S., Sassykova L.R., Nazhipkyzy M., Gabdrashova Sh.E., Kazakov Y.V., Pustovalov I.O., Abdrakova F.Y., Mansurov Z.A., Dalton A.B., Rasayan Journal of Chemistry, 2017, 10(2), 344-348.

21. Bououdina M., Guo Z.X., Materials Science and Engineering: A, 2002, 332(1-2), 210-222.

22. Wildlife Toxicity Assessments for Chemicals of Military Concern. Edited by: Marc A. Williams, Gunda Reddy, Michael J. Quinn, Jr. Mark S. Johnson, Elsevier, 2015, 722p. https://doi.org/10.1016/C2013-0-13473-3.

23. Saleh J.H., Cummings A.M., Safety Science, 2012, 49(6), 767-777.

24. Montgomery Y. C., Focke W.W., Kelly Ch., Propellants, Explosives, Pyrotechnics, 2017, 42(11), 1289-1295.

25. Baiseitov D., Tursynbek S., Tulepov M., Sassykova L., Nazhipkyzy M., Gabdrashova Sh., Kazakov Y., Pustovalov I., Abdrakova F., Mansurov Z., Dalton A., Journal of Chemical Technology \& Metallurgy, 2018, 53(3), 543-548.

26. Tulepov M. I., Gabdrashova Sh. E., Rakhova N. M., Sassykova L. R., Baiseitov D. A., Elemesova Zh., Korchagin M. A., Sendilvelan S., Pustovalov I. O., Mansurov Z.A., Rasayan J. Chem., 2018, 11(1), 287-293.

27. Whiffen B.W., A pyrotechnic delay ignition system for a submarine launched marine signal, 1987. https://doi.org/10.21236/ada188715

28. Pletcher J.L., SPE Reservoir Evaluation \& Engineering, 2002, 5(1), SPE-75354-PA. https://doi.org/10.2118/75354-PA

29. Winsdor C. R., International Journal of Rock Mechanics and Mining Sciences, 1997, 34(6), 919-951.

30. Gabdrashova Sh., Tulepov M., Pustovalov I., Sassykova L., Rakhova N., Spanova G., Hamzina B., Elouadi B., Kazakov Yu., Journal of Chemical Technology and Metallurgy, 2019, 54(3), 650-656.

31. Focke W.W., Tichapondwa Sh.M., Montgomery Y.C., Grobler J.M., Kalombo M. L., Review of Gasless Pyrotechnic Time Delays, Propellants Explos. Pyrotech., 2019, 44, 55-93. https://doi.org/10.1002/prep.201700311

32. Mccollum J., Pantoya M. L., Iacono S. T., ACS Appl. Mater. Interfaces, 2015, 7, 18742-18749. 